\title{
Clinical Assessment of Nursing Care Regarding Hemovigilance in Neonatal Wards and Neonatal Intensive Care Units in Selected Hospitals Affiliated to Shahid Beheshti University of Medical Sciences (2013 - 2014)
}

\author{
Saleheh Tajalli ${ }^{1}$; Manijeh Nourian ${ }^{2,} ;$ Maryam Rassouli $^{2}$; Ahmad Reza Baghestani ${ }^{3}$ \\ ${ }^{1}$ Neonatal Health Research Center, Shahid Beheshti University of Medical Sciences, Tehran, IR Iran \\ 2 Pediatric Nursing Department, School of Nursing and Midwifery, Shahid Beheshti University of Medical Sciences, Tehran, IR Iran \\ ${ }^{3}$ Department of Biostatic Sciences, School of Paramedical Sciences, Shahid Beheshti University of Medical Sciences, Tehran, IR Iran \\ ${ }^{*}$ Corresponding Author: Manijeh Nourian, Pediatric Nursing Department, School of Nursing and Midwifery, Shahid Beheshti University of Medical Sciences, Tehran, IR Iran. Tel: \\ +98-9125446122, E-mail: Manighea@yahoo.com
}

Received: May 4, 2014; Revised: September 12, 2014; Accepted: March 20, 2015

\begin{abstract}
Background: Hemovigilance is a series of surveillance procedures encompassing the entire transfusion chain from the collection of blood and its components to the follow-up of its recipients. It is intended to collect and access information on unanticipated or adverse effects stemming from the therapeutic use of labile blood products. Blood transfusion, particularly in neonates, requires meticulous clinical assessment to ensure safety before, during, and after the procedure. Therefore, it is essential to investigate how nurses and other health care providers implement hemovigilance with a view to elevating the standards of care.

Objectives: The aim of this study, conducted between 2013 and 2014, was to assess nursing care regarding hemovigilance in the neonatal wards and neonatal intensive care units (NICUs) of selected hospitals affiliated to Shahid Beheshti University of Medical Sciences.

Materials and Methods: This descriptive study assessed nursing care concerning hemovigilance in 144 neonates. Data were collected using a checklist at the neonatal wards and NICUs of Mahdiyeh, Mofid, and Imam Hussain hospitals affiliated to Shahid Beheshti University of Medical Sciences. The checklist contained information on the standard of care in relation to neonatal hemovigilance in three components of request, transfusion, and documentation. Descriptive statistics with the Statistical Package for the Social Sciences (version 21) were used to analyze the collected data.

Results: The rates of compliance with the hemovigilance guidelines in terms of request, transfusion, and documentation were $47 \%, 63.2 \%$, and $68 \%$, correspondingly, with a total score of $59.6 \%$ in all areas of research. Accordingly, compliance with hemovigilance guidelines was highest in documentation (68\%), followed by transfusion(63.2\%) and request (47\%).

Conclusions: The overall score of nursing care as regards adherence to the neonatal hemovigilance guidelines was $59.6 \%$ in the present study, indicating a lack of care and failure in training in this regard.
\end{abstract}

Keywords: Nursing Care; Standards; Nursing Audit; Blood Safety; Infant

\section{Background}

Infants are extremely vulnerable in the neonatal period, as is attested to by the high rates of infant mortality. Infants that are hospitalized are likely to have at least one blood transfusion (1). Approximately, 17.5\% of neonates born in hospitals undergo transfusion for various reasons, and $10.7 \%$ of infants receiving blood or blood products are liable to suffer the complications of transfusion (2). Transfusion requires special care ranging from proper adherence to the treating physician's instructions to injection speed control, vital signs monitoring, and documentation of the whole procedure. Negligence will invariably lead to the risk of embolism, sudden increase in blood concentration, impaired oxygenation, and undesirable changes in vital signs (3).

Nurses are among the most important health care providers and as such need to have extensive knowledge and skills to offer quality care (4). The quality of nursing care can be enhanced via regular and thorough evaluations (5). With respect to blood transfusion in neonates, the quality of nursing care is of vital importance (6). Indeed, no task in any given organization can be performed at optimal levels unless there is an effective control system in place (7).

\section{Objectives}

The present study, performed between 2013 and 2014, sought to assess nursing care in relation to compliance with the hemovigilance guidelines in the neonatal wards and neonatal intensive care units (NICUs) of selected hospitals affiliated to Shahid Beheshti University of Medical Sciences.

\section{Materials and Methods}

The current descriptive study assessed nursing care as

Copyright (C) 2015, Iranian Red Crescent Medical Journal. This is an open-access article distributed under the terms of the Creative Commons Attribution-NonCommercial 4.0 International License (http://creativecommons.org/licenses/by-nc/4.0/) which permits copy and redistribute the material just in noncommercial usages, provided the original work is properly cited. 
Tajalli S et al.

regards hemovigilance in 144 neonates by collecting data through a checklist at the neonatal wards and NICUs of Mahdiyeh, Mofid, and Imam Hussain hospitals affiliated to Shahid Beheshti University of Medical Sciences. The checklist consisted of information on the standard of care apropos hemovigilance in three components of request ( 9 items investigating how the request is processed), transfusion (55 items investigating the quality of care during blood transfusion), and documentation (18 items investigating the quality of the documentation of the transfusion procedure). Hemovigilance care includes necessary and unnecessary care. Some care is necessary to inject a certain type of product, so when other products are injected, this is unnecessary care and the score is zero.

The checklist consisted of criteria with two parts as follows:

1. "Yes", which includes:

A. Correct (When a score is given (3) to this part of a task that is carefully and properly done.)

B. Incorrect (When a score is given (2) to this part of a task that is not fully and properly done.)

2. "No" (When a score is given (1) to this part of a task that is done without due care.)

\section{Results}

The findings were discussed in regard to the standards of care in many different areas of hemovigilance in infants hospitalized in neonatal wards and NICUs. Our results showed that the overall rate of compliance with the hemovigilance guidelines in neonates in the hospitals under study was 59.6\% (Table 1). Compliance with hemovigilance was highest in documentation (68\%) (Table 2 ), followed by transfusion (63.2\%) (Table 3 ) and request (47\%) (Table 4).

Table 1. Standard Implementation of Nursing Care Regarding Hemovigilance in the Neonatal Wards and Neonatal Intensive Care Units in All Areas of Research in $2013^{\mathrm{a}}$

\begin{tabular}{lcc}
\hline Nursing Care & Values & Score \\
\hline Request & & 47 \\
\hline Yes, correct & $185(42.8)$ & \\
\hline Yes, incorrect & $37(8.6)$ & \\
\hline No & $210(48.6)$ & 64 \\
\hline Transfusion & & \\
Yes, correct & $2047(37.1)$ & \\
\hline Yes, incorrect & $315(5.7)$ & 68 \\
\hline No & $1073(19.4)$ & \\
\hline Documentation & $185(42.8)$ \\
\hline Yes, correct & $37(8.6)$ & \\
\hline Yes, incorrect & $210(48.6)$ & 59.6 \\
\hline No & \\
\hline Total & \\
\hline
\end{tabular}

\footnotetext{
$\mathrm{a}$ Values are presented as No. (\%) or \%.
}

Table 2. Relative Frequency of the Documentation Component of the Study Checklist to Assess Nursing Care Standards Regarding Hemovigilance for the Blood Products Administered to the Neonates in the Neonatal Wards and Neonatal Intensive Care Units in the Study in $2013^{\text {a }}$

\begin{tabular}{lc}
\hline Documentation Nursing Care & Values \\
\hline Necessary & \\
\hline Yes, correct & $336(38.9)$ \\
\hline Yes, incorrect & $111(12.8)$ \\
\hline No & $124(14.4)$ \\
Unnecessary & $293(33.9)$ \\
\hline Total & $864(100)$ \\
\hline Score & 68 \\
\hline
\end{tabular}

a Values are presented as No. (\%) or \%.

Table 3. Relative Frequency of the Transfusion Component of the Study Checklist to Assess Nursing Care Standards Regarding Hemovigilance for the Blood Products Administered to the Neonates in the Neonatal Wards and Neonatal Intensive Care Units in the Study in $2013^{\text {a }}$

\begin{tabular}{lc}
\hline Transfusion Nursing Care & Values \\
\hline Necessary & \\
\hline Yes, correct & $1999(36.2)$ \\
\hline Yes, incorrect & $315(5.7)$ \\
\hline No & $1105(20.0)$ \\
\hline Unnecessary & $2101(38.1)$ \\
\hline Total & $5520(100)$ \\
Score & 63 \\
\hline
\end{tabular}

${ }^{a}$ Values are presented as No. (\%) or \%.

Table 4. Relative Frequency of the Request Component of the Study Checklist to Assess Nursing Care Standards Regarding Hemovigilance for the Blood Products Administered to the Neonates in the Neonatal Wards and Neonatal Intensive Care Units in the Study in $2013^{\mathrm{a}}$

\begin{tabular}{lc}
\hline Request Nursing Care & Values \\
\hline Necessary & $185(42.8)$ \\
Yes, correct & $37(8.6)$ \\
\hline Yes, incorrect & $210(48.6)$ \\
No & $0(0)$ \\
Unnecessary & $432(100)$ \\
Total & 47 \\
\hline Score &
\end{tabular}

${ }^{\mathrm{a}}$ Values are presented as No. (\%) or \%. 
Tajalli S et al.

\section{Discussion}

The findings of this study showed that the overall rate of compliance with the standards of nursing care regarding hemovigilance in the neonatal units and NICUs was $59.6 \%$. Based on our three-part checklist, compliance with the hemovigilance guidelines in neonates was highest in documentation (68\%), followed by transfusion (63.2\%) and request (47\%) (Table 1$)$. Additionally, the results demonstrated that the compatibility of the separate items related to the standards of nursing care concerning hemovigilance was $64 \%$.

The overall rate of neonatal hemovigilance by the nursing staff in neonatal wards was 58\%; the corresponding rates apropos documentation, transfusion and request were $70 \%, 58 \%$ and $48 \%$ (Table 5) and rate of neonatal hemovigilance by the nursing staff in $\mathrm{NICU}_{\mathrm{S}}$ was $63 \%$; the corresponding rates apropos documentation, transfusion and request were $68 \%, 64 \%$ and $42 \%$ (Table 6 ).

One reason might be the significance accorded to documentation in the hospital accreditation process. It seems that the nursing staff was able to deliver standard hemovigilance in terms of documentation; however, the same standards of hemovigilance care were not brought to bear to the other two components of the checklist, i.e. request and transfusion.

The standard checklist for blood transfusion and blood products request contains two separate items of emergency and non-emergency to be filled by medical personnel. Nonetheless, recent research indicates that the rate of compliance with the standards of hemovigilance in terms of request is $47 \%$. More often than not a request for blood transfusion is made in a non-emergency situation on the morning shift and transfusion is performed on the night shift. In most circumstances, the request for

Table 5. Standard Implementation of Nursing Care Regarding Hemovigilance in the in Neonatal Wards in All Areas of Research in 2013

\begin{tabular}{lc}
\hline Nursing Care & Score, \% \\
\hline Request & 48 \\
Transfusion & 58 \\
Documentation & 70 \\
Score & 58 \\
\hline
\end{tabular}

Table 6. Standard Implementation of Nursing Care Regarding Hemovigilance in the Neonatal Intensive Care Units in All Areas of Research in 2013

\begin{tabular}{lc}
\hline Nursing Care & Score, \% \\
\hline Request & 42 \\
Transfusion & 64 \\
Documentation & 68 \\
Score & 63 \\
\hline
\end{tabular}

transfusion and subsequently the administration of the transfusion are done by two different nurses, hence the difference in the standards as regards request on the one hand and transfusion and documentation on the other. There have been reports of the failure of the health care providers to inform the child's mother about the possible side effects of blood transfusion such as allergy symptoms (chills) or to obtain informed consent $(8,9)$. Therefore, more attention should be paid to family-centered nursing care in the care of infants (9). Requesting blood transfusion should be in accordance with clinical guidelines so as to reduce the possibility of complications (10). Based on the results of a study, the intravenous line was not washed before transfusion in $66.7 \%$ of the cases. Guidelines stipulate that intravenous lines must be washed with $1 \mathrm{cc} / \mathrm{kg}$ of normal saline in order to prevent complications. Also, it is advisable that peripheral blood transfusion be conducted using 18- to 20-guage angiocatheters or multilumen central venous catheters. Blood products should also be used in separate sets. The use of leukocyte reduction filters can reduce the risk of allergic reactions (7,11). In the present study, all the transfusion procedures were performed using a specific filter. The results of an assessment conducted by the Royal College of Physicians of Great Britain in blood centers recommended the use of wrist bands on neonates for better control of transfusion (11).

In one study on transfusion standards, $60.4 \%$ of the transfusion administrators failed to wash their hands, 93.8\% failed to wear gloves, and $100 \%$ failed to wear masks and gowns, which runs contrary to guidelines demanding the practice of hand washing and the use of gloves, masks, and gowns before transfusion administration (9). These findings are consistent with the results of the current study. It seems that a lack of awareness among nursing staff and unavailability of hand-washing dispensers are the reasons for the failure (12). For all the advances and successes in health care in recent years, there are still many shortcomings regarding adherence to clinical guidelines and standards $(11,13)$. The findings of a study by Motta et al. (9), along with the results of theoretical research, are consistent with our research.

Based on the results of a study, the blood products were not warmed up sufficiently in $6.3 \%$ of the cases, which highlights the negligence in compliance with the guidelines on the part of the nursing staff. It is necessary to warm up blood products to $37^{\circ} \mathrm{C}$ before rapid or large-volume infusions to neonates. It is wrong to warm up blood products by hands or by placing them under a blanket or on a radiator; the only method recommended for this purpose is to use blood-warming devices (11).

In the present study, the rate of compliance with hemovigilance guidelines was highest in documentation (68\%). Another study reported that in the documentation of transfusion, factors such as energy and time constraints, insufficient knowledge, improper division of labor among the nursing staff, and inadequate supervision can have a negative impact (10). 
Khodam et al. (12) stated that the continual education of the nursing staff can considerably enhance the quality of documentation.

As a result, it seems that educating the nursing staff about hemovigilance guidelines in neonates can augment the standard of care in neonatal units and NICUs.

\subsection{Outcome}

The results of the present study revealed that the rates of compliance with the hemovigilance guidelines in neonates in terms of request, transfusion, and documentation were $47 \%, 63.2 \%$, and $68 \%$, correspondingly, with a total score of $59.6 \%$ in all areas of the research, in the neonatal wards and NICUs of Mahdiyeh, Mofid, and Imam Hussain hospitals affiliated to Shahid Beheshti University of Medical Sciences. Accordingly, we recommend that health care providers and, in particular, nursing staff be continually trained in terms of the hemovigilance guidelines so that the standards of care can be elevated. Further research in this area will provide more information on the status of hemovigilance in NICUs.

\section{Acknowledgements}

We thank Ms. Masom Pour, Dr. Karimi, Dr. Balali, and the Hemovigilance Committee of The Iranian Blood Transfusion Organization. Special thanks are also due to the supervisors, nurses, midwives, and hospital staff of Shahid Beheshti University of Medical Sciences.

\section{Authors' Contributions}

Study concept and design: Saleheh Tajalli, Manijeh Nourian, and Maryam Rassouli; Acquisition of data: Saleheh Tajalli and Ahmad Reza Baghestani; Analysis and interpretation of data: Saleheh Tajalli and Ahmad Reza Baghestani; Drafting of the manuscript: Saleheh Tajalli; Critical revision of the manuscript for important intellectual content: Saleheh Tajalli, Manijeh Nourian, and Maryam
Rassouli; Statistical analysis: Saleheh Tajalli and Ahmad Reza Baghestani; Administrative, technical, and material support: Saleheh Tajalli, Manijeh Nourian, and Maryam Rassouli; Study supervision: Saleheh Tajalli, Manijeh Nourian, and Maryam Rassouli.

\section{Funding/Support}

This study was supported by Shahid Beheshti University of Medical Sciences, Tehran, IR Iran.

\section{References}

1. Chen HL, Tseng HI, Lu CC, Yang SN, Fan HC, Yang RC. Effect of blood transfusions on the outcome of very low body weight preterm infants under two different transfusion criteria. Pediatr Neonatol. 2009;50(3):110-6.

2. Slonim AD, Joseph JG, Turenne WM, Sharangpani A, Luban NL. Blood transfusions in children: a multi-institutional analysis of practices and complications. Transfusion. 2008;48(1):73-80.

3. Tinsley RH. Blood disease. 18 ed. United States of America: McGraw-Hill; 2012.

4. Thelan LA. Critical Care Nursing Diagnosis And Management. 4 ed Mosby Co. Louis; 2002.

5. Marquis BL, Huston CJ. Leadership roles and management function in nursing. Theory and application. 7 ed. Philadelphia: Lippincott Co.;

6. Wallis JP, Wells AW, Chapman CE. Changing indications for red cell transfusion from 2000 to 2004 in the North of England. Transfus Med. 2006;16(6):411-7.

7. Robert M. Nelson textbook of pediatrics.19 ed. Philadelphia: Malassezia; 2011. pp. 703-31.

8. Kasat K, Hendricks-Munoz KD, Mally PV. Neonatal red blood cell transfusions: searching for better guidelines. Blood Transfus. 2011;9(1):86-94.

9. Motta M, Testa M, Tripodi G, Radicioni M. Changes in neonatal transfusion practice after dissemination of neonatal recommendations. Pediatrics. 2010;125(4):e810-7.

10. Reynolds P. Blood Transfusion Policy Neonatal Unit. Neonatal Paediatrician Peter Hospital's Booklet; 2007.

11. Satarzadeh A, Pasha Beyg M. [Develop and implement the guidance on quality of nursing records CCU shahid Mostafa Khomeini hospital]. Tehran: Tarbiat Modarres University; 2003.

12. Khodam H, Sanago A, Joibari L. CME impact on quality of nursing records.J of Gorgan Uni of Med Sci. 2002;8(30):65-9.

13. Johen D, Brenda G, Teresa Hariss MT. Technical Manual.17 ed. Philadelphia: Maryland; 2011. pp. 171-90. 